Journal of Engineering and Applied Sciences 15 (7): 1604-1608, 2020

ISSN: 1816-949X

(C) Medwell Journals, 2020

\title{
The Development of Research Grant Management System
}

\author{
Hamidon Katan and Nurul Nuha Che Husin \\ Malaysian Institute of Information Technology, Universiti Kuala Lumpur, \\ Kuala Lumpur, Malaysia
}

\begin{abstract}
The management of universities requires the research grant data at quarterly basis for monitoring and reporting purposes. UniKL Centre of Research Institute (CoRI) is in charge of collecting and reporting of the research grant data. Currentlym this process is done manually by distributing a form to the academicians and ask them to fill in the form. Every time they ask for the grant data, the form will be different. Using this system, CoRI will be able to track and store the academics historical and current data and status. Academics could update their application status through the system. CoRI will update the information about the grant application in the system and also to provide the up-to-date status report to the management.
\end{abstract}

Key words: Grant, research grant, grant application, CoRI, management, academics

\section{INTRODUCTION}

Universiti Kuala Lumpur (UniKL) is a leading university in engineering technology, established on 20 August, 2002. Wholly owned by Majlis Amanah Rakyat (MARA) an agency under the Ministry of Rural and Regional Development (KKLW), Malaysia, the university is given the mandate to upgrade the status of technical education in Malaysia by the government (Ahmad and Farley, 2014). As the nation expects more from a technical higher learning institutions, UniKL mould its graduates with strong technological knowledge and astute entrepreneurial skills who would later fulfill the current demand of the industries. UniKL's 14 branch institutes offer various foundation, diploma, undergraduate and postgraduate programmes.

At UniKL, research and development is managed by Centre for Research and Innovation (CoRI) to facilitate research activities which include exploration for research funds, research awareness training and development of research policy. In order to facilitate the research and innovation in UniKL MIIT, it is proposed that a system should be developed to collect data from the academicians, since, they have the research activities data at personal level. Top management need to know all research activities by the academicians in UniKL MIIT (as well as other branch institutes) but the scope of this system would be focused on the academician's funding only. The data of funding to be collected and managed by the system is on all research management in the UniKL MIIT.

This system for lecturers to apply the grant for benefit of UniKL MIIT. Through this system, admin and user can keep connected to get update about grant applying followed by the due date. This system is proposed because most of lecturers need a system which is able to manage the grant applying through the system. Grant management system needs to developed to make admin and lecturer (user) to make them easier to update and check. The way of applying grant become easier, faster and efficient.

This project will bring significant benefits to both research and innovation section as the administrator that responsible for lecturer's research activity and lecturers as the user. UniKL MIIT will have a better way to manage and collect grant data from users. Users will get benefit from the new way to manage and update their grant applying records. It is hoped that this study will be contributing to UniKL MIIT by providing an easy to understand and faster way to manage and collect grant details.

Problem statement: UniKL MIIT Research and Innovation section (R\&I) needs to know the academician's articles or journals publication at monthly and quarterly basis. The top management (i.e., comprises of the president, the deans and the directors of UniKL institutes and centres) requires the data commonly at quarterly basis for monitoring purposes.

UniKL MIIT Research and Innovation section (R\&I) needs to know the academician's articles or journals publication at monthly and quarterly basis. The top management (i.e., comprises of the president, the deans and the directors of UniKL institutes and centres) requires the data commonly at quarterly basis for monitoring purposes. CoRI is in charge of collecting the data and this is done manually by distributing a form to the academicians and ask them to fill in the form and hand the

Corresponding Author: Hamidon Katan, Malaysian Institute of Information Technology, Universiti Kuala Lumpur, Kuala Lumpur, Malaysia 
forms (i.e., papers) back to them, through R\&I. Every time they ask for the publication data, the form will be different. For example, last year (i.e., 2015) the form only has 4 detail columns but this year the form has 7 detailed columns. By this method, they might have a late response or submission from the academicians because sometimes the form does not reach them possibly due to being on leave or outstation. As a result, the academicians may miss the deadline of submission to R\&I, causing lack of updated data to be reported to the top management.

On the other hand, there are academicians who are not willing to provide the required data, due to personal reasons or technical difficulties. The tedious process of filling in the form in various ways every time the data is needed seems to be a hindrance to the academician's daily work. At times, the academicians may not have their own systematic or organised records on their publications, partly due to the small data they have in hand hence there is no need for such system at their personal level. However, as time passes, the personal data on publication would be growing in numbers and this would require a proper system even at their personal level.

From the situation, the current process of data collection is not efficient nor effective. This is because the data keyed in by the academicians are often in Microsoft Word or Excel format and once the R\&I officer receives the form, he or she has to rekey in all the data in the computer to compile the whole UniKL MIIT data. UniKL MIIT R\&I section also cannot keep track the research activities of any academicians at any one time and nor the number of publications at monthly or quarterly basis. Hiring only one officer to do the job of data compilation for more than 100 academicians per institute like UniKL MIIT makes the case worse.

\section{Literature review}

Information technology: The term information technology was coined by the Harvard Business Review in order to make a distinction between purpose-built machines designed to perform a limited scope of functions and general-purpose computing machines that could be programmed for various tasks. As the IT industry evolved from the mid-20th century, it encompassed transistors and integrated circuits, computing capability advanced while device cost and energy consumption fell lower, a cycle that continues today when new technologies emerge.

IT software and hardware: IT includes several layers of physical equipment (hardware), virtualization and management or automation tools, operating systems and applications (software) used to perform essential functions. User devices, peripherals and software such as laptops, smartphones or even recording equipment can be included in the IT domain. IT can also refer to the architectures, methodologies and regulations governing the use and storage of data.

Business applications include databases like SQL Server, transactional systems such as real-time order entry, email servers like Exchange, web servers like Apache, customer relationship management and enterprise resource planning systems. These applications execute programmed instructions to manipulate, consolidate, disperse or otherwise affect data for a business purpose. Computer servers run business applications. Servers interact with client users and other servers across one or more business networks. Storage is any kind of technology that holds information as data. Information can take any form including file data, multimedia, telephony data and Web data, data from sensors or future formats. Storage includes volatile Random Access Memory (RAM) as well as non-volatile tape, hard disk and solid-state flash drives.

IT architectures have evolved to include virtualization and cloud computing where physical resources are abstracted and pooled in different configurations to meet application requirements. Clouds may be distributed across locations and shared with other IT users or contained within a corporate data center or some combination of both deployments.

Study in computer science: Many young students who turn to higher education look forward to the day when the degree they receive will expedite a "good" job with a salary that will enable them to buy a high social status. Higher education is perceived amongst students as a tool for achieving benefits and various goals they have set for themselves, not necessarily as a goal in and of itself. Teacher training in Israel is done in designated colleges. In the college that was chosen for this study the students who are training to be computer science teachers must also train as mathematics teachers as well. Therefore, upon completing their studies the students receive a bachelor of education degree in both mathematics and computer science. The integration of these two subjects led us to conduct this study in order to examine the expectations and attitudes of the students who learn in this program. What do they expect from the program and from themselves in the present and in the future.

These are method how computer science student view their studies. First, course of study. The study took place in Israel during the course of 2013; it was conducted using the qualitative method of "Field Based Theory". This method examines how processes affect people and allows for the creation of new categories and subjects that arise from the field in the course of the study (Egoza, 2014). Second, structure of the 
questionnaire. In this study the interviews were conducted using semi-structured questions where the best of the students were asked questions about their courses in the program for computer science teaching. The subjects that were asked were: why had they chosen to learn computer science for teaching, their expectations of their achievements in relation to the program and their aspirations for the future. Third, data processing. In this study interviews were conducted with 14 of the best students of the computer science for teaching program. Analysis of the results was based on the content of the interviews with the students.

Management information system: Currently one of the urgent topics in this sphere can be considered the creation of a unified conceptual and categorical apparatus of information management, summarized in a logically connected international system which will enable the manager to navigate the numerous international abbreviations and will not just use their literal translation and to understand correctly the essence. A hierarchical classification of systems of information management in accordance with their functionality will make it possible to consistently build the logic of the management of the company (model, paradigm) and according to the general rules to accompany its development in a formalized way with the help of modern information systems.

Practical importance of the proposed systematization of the conceptual and categorical apparatus is disclosed in the article by analyzing the information flows in the investment and construction business that is increasing share in the macroeconomics of Russia. Due to the specificity of this area of the economy, based on performance-oriented approach as one of the most effective modern approaches to management, the main tendencies of development of systems management of construction projects in the general system of the global network economy are specified. For example, construction design introduces relevant concepts of the international system, discusses the various levels of such automated control systems, the relationship between the individual systems, their advantages and disadvantages. For the modern manager in the era of a global networked economy, along with such basic concepts as: information, binary arithmetic, digital technology, computer programs, programming languages, text and table processors, databases, visualization software and image processing, video, sound (multimedia), electronic mail services and electronic means of World Wide Web communication, highly specific management information English terms and international terms become commonly used.

Funding and grant: Funding is providing financial resources to finance a need, program or project. In general, this term is used when a firm fills the need for cash from its own internal reserves and the term 'financing' is used when the need is filled from external or borrowed money. Grant of authority to an agency, department or unit to incur monetary obligations and to pay for them. Grants, generally are not refunded funding and an international body to achieve clearly defined obj 2020 for education, culture and mobility (Long mechanism of the European Economic Area (EEA)-funds provided by the government of member Norway, Iceland and Liechtenstein (Amran et al., 2014). The funding of public higher education institutions (hereinafter "universities") has experienced major changes over the last 3 years. The most important changes occur in funding from the Ministry of Education, Youth and Sports of the Czech Republic (hereinafter "MEYS") when the algorithms change every year, individual input variables and their amount are being reviewed which in consequence significantly affects the amount of contributions and subsidies that a university receives in the relevant year. Universities are thus, forced to respond flexibly and adapt to sudden fluctuations in their funding sources, resulting in the increased awareness of the growing need for the implementation and use of new methods of financial management (Estermann and Pruvot, 2011).

\section{MATERIALS AND METHODS}

The methodology for the deveopment of this system is using Rapid Application Development Model (RAD) (Fig. 1). The requirement phase is primarily consisted of combination of the system planning and analysis stage, the stage is more or less the planning stage of which the planning is done with the development underway and the team agrees on the parts that are going to be put in the software. The client, developers and team managers agree on the For this project, the mission statement is to develop a web-based system for UniKL MIIT research and innovation section and the academicians to record and compile the data of the academician's research activities for better.

User feedback is gathered with heavy emphasis on determining the system architecture to allows initial modelling and prototypes to be created and this step is repeated as often as necessary as the project evolves. This system uses programming language PHP, HTML and MySQL. The goal at this level is to evaluate whether the

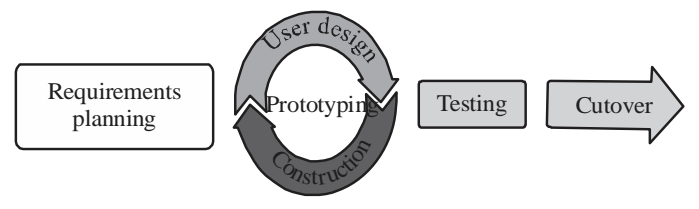

Fig. 1: Rapid Application Development (RAD) Model 
system has complied with all of the outlined requirements and to see that it meets the client's satisfaction. The testing and turnover stage allows for a reduced time in the overall testing of the prototypes created. By this point in the RAD Model, most of the components have already been examined, so, major problems with the prototype are not likely.

\section{RESULTS AND DISCUSSION}

The output that was developed for this project: interface user register shown in Fig. 2. Figure 3 shows interface user login. Figure 4 show interface user homepage. Figure 5 shows interface user insert grant data. Figure 6 shows interface list of grants for user.

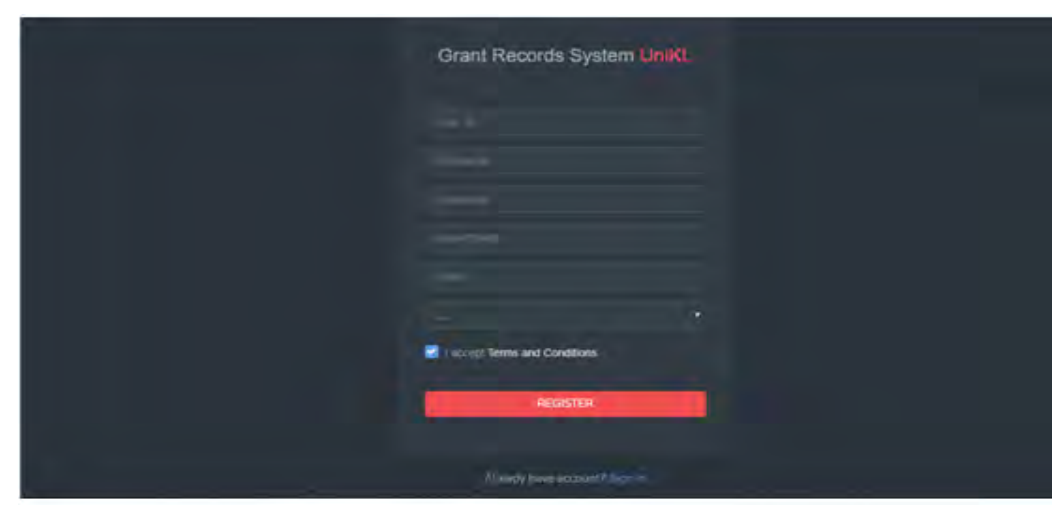

Fig. 2: Interface user register

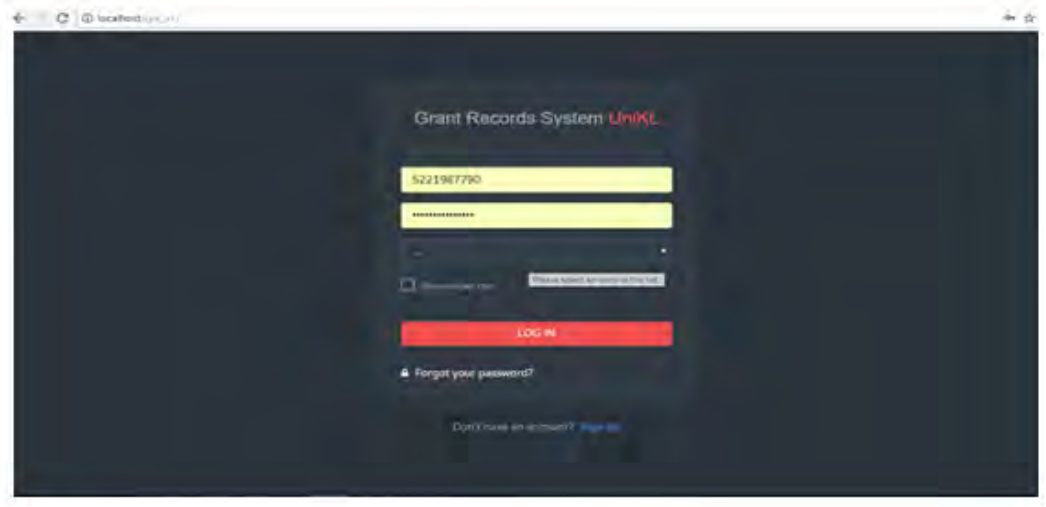

Fig. 3: Interface user login

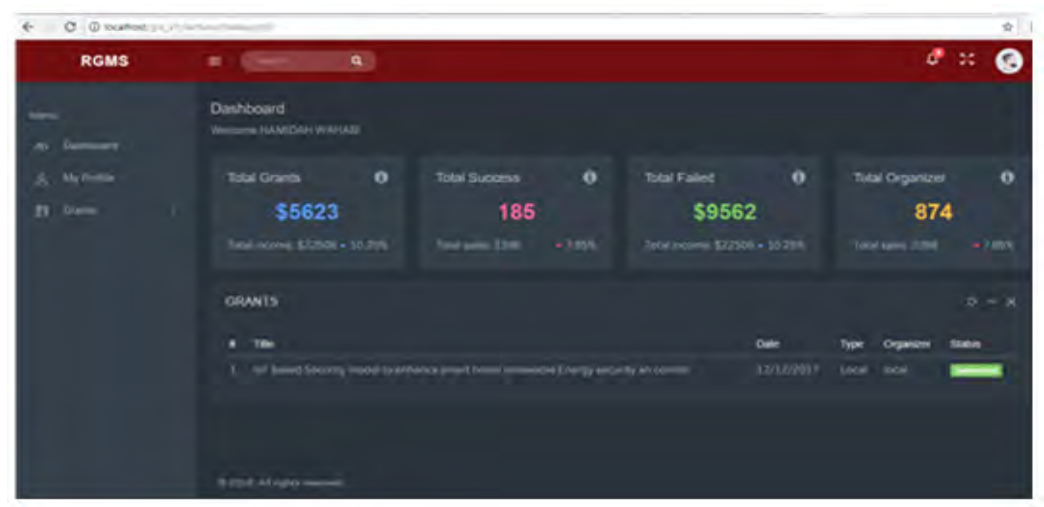

Fig. 4: Interface user homepage 


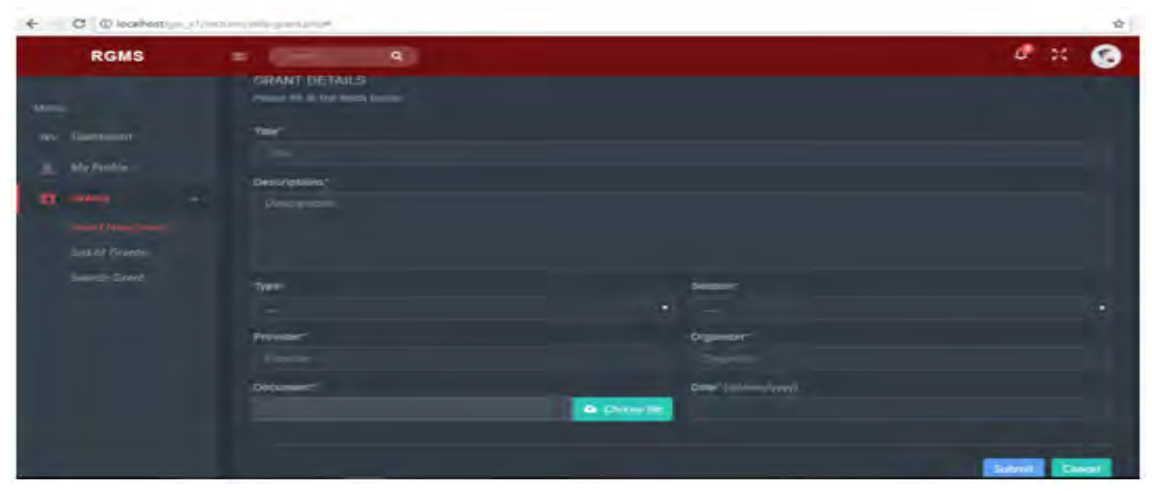

Fig. 5: Interface user insert grant data

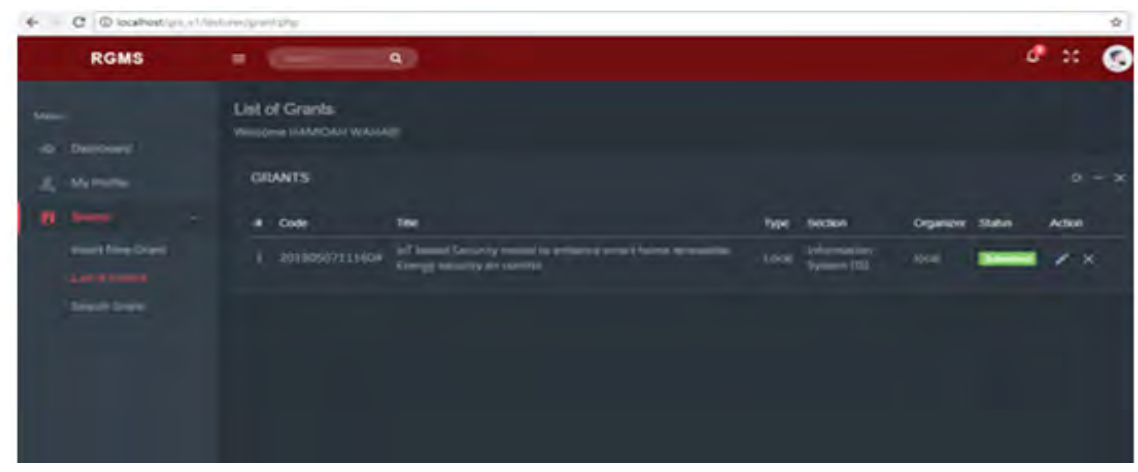

Fig. 6: Interface list of grants for user

\section{CONCLUSION}

Research grant management system which was developed to ease the management of CoRI of UniKL has met all of its objectives (Jacob and Lefgren, 2011). The academics are able to input their reseach grant application activities and also able to update their progress. As for CoRI, they are able to extract the information in real time for the management to decide on the future directions, since, research activities contribute a high percentage towards MyRA and subsequently contributes significantly to university ranking.

\section{REFERENCES}

Ahmad, A.R. and A. Farley, 2014. Funding reforms in Malaysian public universities from the perspective of strategic planning. Procedia Social Behav. Sci., 129: 105-110.
Amran, F.H., I.K.A. Rahman, K. Salleh, S.N.S. Ahmad and N.H. Haron, 2014. Funding trends of research universities in Malaysia. Procedia Soc. Behav. Sci., 164: 126-134.

Egoza, W., 2014. How Computer science students view their studies?. Procedia Soc. Behav. Sci., 143: 204-206.

Estermann and Pruvot, 2011. Funding trends of research universities in Malaysia. Proceedings of the International ICAS 2014 Conference on Accounting Studies, August 18-19, 2014, ICAS, Kuala Lumpur, Malaysia, pp: 126-134.

Jacob, B.A. and L. Lefgren, 2011. The impact of research grant funding on scientific productivity. J. Pub. Econ., 95: 1168-1177. 